\title{
Superhéroes y el futuro de la especie humana. Una mirada bioética al filme $X$-Men: dias del futuro pasado
}

\author{
X-Men: Days of Future Past | Bryan Singer | 2014 \\ Natalia Pedraza* \\ Pontificia Universidad Javeriana, Colombia
}

Recibido: 22 de mayo 2019; aceptado: 20 de junio 2019

\begin{abstract}
Resumen
Los filmes de superhéroes nos muestran actitudes significativas, encarnadas en personajes que, como principal objetivo, tienen la obligación de decidir ante situaciones en las cuales sus principios morales se ponen en cuestión. Sus vidas se mueven entre un sinnúmero de aspiraciones y miedos que, usualmente, terminan poniendo en riesgo la supervivencia de la especie humana. Así, el superhéroe debe ser considerado por la bioética, ya que, este cine de ciencia ficción nos enfrenta a situaciones dilemáticas en las que nuestras concepciones sobre temas como la naturaleza, la supervivencia y las intervenciones a la especie humana nos demandan cuestionarnos acerca de qué podemos permitir, favorecer o prohibir, acerca del uso de, por ejemplo, la biotecnología sobre vidas humanas y no humanas, resaltando que, los límites entre humanos y no humanos se han vuelto más inseguros.
\end{abstract}

Palabras Clave: Superhéroes | Cine | Ciencia ficción | Bioética | Modificación genética

Superheroes and the future of human species. A bioethical look at the X-Men film: days of the future past

\begin{abstract}
Superhero films show us significant attitudes, embodied in characters that, as the main objective, have the obligation to decide in situations where their moral principles are put in question. Their lifes move among a myriad of aspirations and fears that usually end up putting the survival of the human species at risk. Thus, the superhero must be considered by bioethics, since, this science fiction film confronts us with dilemmatic situations in which our conceptions on topics such as nature, survival and interventions to the human species, demand us to question ourselves about of what we can allow, favor or prohibit, about the use of, for example, biotechnology on human and non-human lifes, highlighting that the limits between human and non-human have become more insecure.
\end{abstract}

Key Words: Superheroes | Movies | Science fiction | Bioethics | Genetic modification

\section{Introducción}

Constantemente vamos de la bioética al cine para pensar en lo que nos depara el futuro. Por ejemplo, el cine de ciencia ficción nos permite reflexionar acerca de los límites entre humanos y superhumanos (superhéroes). Inicialmente, este mostraba una postura más dogmática respecto a temas como la relación entre humanos y no humanos, mientras que, actualmente, se ha vuelto más inseguro (Lipovetsky y Serroy, 2009) respecto a esas fronteras que los distancian.

El cine de ciencia ficción se ha enfocado en resaltar los peligros a los que nos podemos enfrentar al disminuir esos límites. Esto se debe a la creencia de que la humanidad se desdibuja, pues en los principios "las películas de ciencia ficción mostraban la perfección como igual a la monstruosidad, mientras que, películas posteriores ponen en duda la idea de que el genoma perfecto realmente puede conducir a la persona perfecta" (Kirby, 2008, p. 84).

Por esto, consideramos de gran importancia abordar el cine de ciencia ficción, y específicamente, el de superhéroes. Porque se ha configurado como un espacio prolífero para analizar situaciones ficticias, donde se hacen patentes las posibles implicaciones bioéticas de aceptar, por ejemplo, la existencia de seres modificados genéticamente, de robots que puedan tomar decisiones o de someter a experimentación a unos individuos, porque hacen parte de una población minoritaria o vulnerable.

*nataliapedrazaj@outlook.com 


\section{El cine de superhéroes}

Muchas de las películas que más se lanzan al mercado se basan en los cómics de superhéroes. Los cuales constituyen una de esas formas de arte originales de Estados Unidos que, han influenciado otras culturas alrededor del mundo. Dentro de los cómics existe un género específico denominado tecnocómics que es presentado por Biniek y Lynch (2005) en la Encyclopedia of science, technology and ethics, como muy cercano a la ciencia ficción, y que sirve de dos formas: "la primera, como espejo de la sociedad, y la segunda, como fórmula de reflexión alrededor de preguntas relacionadas con ciencia, tecnología y ética” (p. 1893). Esos cómics expresan ideas filosóficas enmarcadas en la denominada cultura pop, ideas como la responsabilidad individual, la justicia, las emociones humanas, los deseos de perfeccionamiento, entre otras, presentadas de modo fascinante y que, merecen ser estudiadas (Morris y Morris, 2010).

Las películas de superhéroes están ambientadas en escenarios de aventura, acción y ciencia ficción. Según lo muestra el portal IMDB ${ }^{1}$ bajo el término superhéroes (superhero en inglés) se encuentran al menos 100 películas desde el año 2000 y, aproximadamente, 135 desde el año $1978 .{ }^{2}$ No hay claridad si este boom cinematográfico se ha desarrollado de forma independiente o debido a anuncios públicos como el de la culminación del primer borrador del genoma humano.

Consideramos que, no es casual que en esta época haya una producción tan amplia de películas de superhéroes y que, además, mantengan unas características específicas que, en ocasiones, pareciese que todas ellas hablaran de lo mismo. Como menciona Velasco (2015):

En términos de teoría de la ficción, los protagonistas de los cómics [y de las películas] de superhéroes son víctimas de su propio principio de verosimilitud (funcionan, pero no son). Como ocurre con el héroe pecador (hybris es la palabra) de la mitología griega, acarrean el castigo de la inhumanidad. [...] Un gran poder, un acto heroico, implica una singularización excesiva (p. 58).

De esta forma, el superhéroe es un tema singular o diferente que, requiere de una constante repetición para ser apropiado, para que eso que consideramos ciencia ficción y, por lo tanto, como algo que podría ser impensable empiece a ser parte de la realidad cotidiana del espectador. Como menciona Deleuze (2002) "la repetición es la potencia de la diferencia y de la diferenciación, [porque] condensa las singularidades" (p. 331). A lo que Velasco (2015) agrega que, todo intento de singularizar una narrativa que es serial por naturaleza es imposible de acometer, [pues] el estilo del cómic serial parte de unas marcas de la repetición especialmente patentes $\mathrm{y}$, sin embargo, aspira a la singularidad constante a través del auxilio del realismo (p. 63).

La apropiación de este tipo de filmes se ve influenciada porque el espectador puede situar al personaje como un actor que, haría de la sociedad lo que podemos aspirar a ser o lo que, por ningún motivo, podríamos permitir se hiciera de ella. De este modo, como señala Umberto Eco (1984),

El héroe dotado con poderes superiores a los del hombre común es una constante de la imaginación popular, desde Hércules a Sigfrido, desde Orlando a Pantagruel y a Peter Pan. A veces las virtudes del héroe se humanizan, y sus poderes, más que sobrenaturales, construyen la más alta realización de un poder natural, la astucia, la rapidez, la habilidad bélica, o incluso la inteligencia silogística y el simple espíritu de observación, como en el caso de Sherlock Holmes (pp. 257-258).

Una de las características más importantes de los superhéroes es que son modelos morales de la sociedad a la que pertenecen. Ellos deben hacer lo que la sociedad les exige, los superhéroes no robarían una tienda, un personaje como

El Superman de las historietas ilustradas [...] es el héroe superdotado que emplea sus fabulosas posibilidades de acción para realizar un ideal de absoluta pasividad, renunciando a todo proyecto que no haya sido homologado previamente por los catadores del buen sentido oficial, convirtiéndose en ejemplo de una honrada consciencia ética, desprovista de toda dimensión política, Superman no aparcará nunca su coche en una zona prohibida ni organizará nunca una revolución (Eco, 1984, p. 14).

En las diferentes historias deben decidir entre hacer un bien u otro bien. La franja que distingue una acción de otra, no se muestra tan fácil como para tener claridad acerca de cómo actuar. Así, los superhéroes deben optar por salvar a un grupo de bumanos aunque eso implique destruir una ciudad, o escoger entre salvar a la mujer que aman o a un grupo de niños, como se puede apreciar en películas como Spider-man (Raimi, 2002) o Ironman (Favreau, 2008). Estas situaciones exponen típicos problemas éticos que trata el utilitarismo. Siguiendo las palabras de Morris T. y Morris M. (2010):

Los mejores cómics de superhéroes, además de resultar tremendamente entretenidos, introducen y desarrollan de forma vívida algunas de las cuestiones más importantes e interesantes a las que se enfrentan todos los seres humanos: cuestiones relativas a la ética, a la responsabilidad personal y social, la justicia, la delincuencia y 
el castigo, el pensamiento y las emociones humanas, la identidad personal, el alma, el concepto de destino, el sentido de nuestras vidas, cómo pensamos sobre la ciencia y la naturaleza [...] (p. 14).

En sociedades distópicas, ${ }^{3}$ donde algunas películas y cómics de superhéroes son ambientadas, les puede corresponder a estos personajes especiales salvar a la humanidad de aquellas cosas que pueden ser tomadas como riesgosas para la especie humana. Este tipo de filmes nos dotan de escenarios propicios para abordar los ideales que, se esperan cumplir en el futuro: como la erradicación de enfermedades o seres tan optimizados que tengan características completamente determinadas por alguien que las escogió para ellos, así

si en nuestro mundo existieran de verdad personas con superpoderes extraordinarios ¿cómo reaccionaríamos ante ellos?, ¿cómo creemos que afectarían a nuestra vida y actitudes? [...] ¿Cómo reaccionaría si se le ofreciera la ocasión de alterar genéticamente a su bebé, en sus primeros estadios embrionarios, para potenciarlo de modo que fuera capaz de hacer el bien a una escala inédita [...] o causar daños terribles? La investigación genética y la nanotecnología quizá no tarden en despertar, en el mundo real, algunos temas centrales con los que los cómics de superhéroes han estado lidiando desde hace mucho tiempo. ¿Estamos acaso preparados, filosóficamente, para un futuro tan radicalmente potenciado? (Morris y Morris, 2010, p. 15).

Como podemos apreciar, en las películas de superhéroes afloran constantemente los problemas éticos. Aunque, inicialmente, no son películas que, se toman como referentes para llevar a cabo discusiones de orden ético, ofrecen elementos que deberían ser tenidos en cuenta para ello. Muchos de los superhéroes demuestran el deseo de usar sus habilidades de forma correcta y aceptan cargar una responsabilidad sobre otros a quienes sus poderes afectan. Por ejemplo, "héroes como el casi omnipotente Profesor X, parecen estar siempre defendiendo y compartiendo su creencia de que aquellos que posean sus habilidades no deben explotar a aquellos que no las tienen" (Biniek y Lynch, 2005, p. 1893).

En consecuencia, entremos a considerar un ejemplo fílmico en el que esos superseres son los protagonistas. Veamos cómo nos invitan a pensar problemas, como el encuentro y la contraposición entre el desarrollo biotecnológico y la bioética, a partir de lo que viven los superhéroes mutantes, teniendo como referente $X$-Men: días del futuro pasado (Singer, 2014). A continuación, nos sumergiremos en su mundo o deberíamos decir: ¿nuestro mundo?

\section{$\mathrm{X}-\mathrm{Men}$ días del futuro pasado: orígenes y relevancia para la bioética}

La película $X$-Men: días del futuro pasado hace parte de una de las sagas que se reúnen bajo el título $X$-Men. Este grupo de filmes son valiosos porque tienen unas características particulares útiles para el análisis bioético. La primera es que son protagonizadas por superhéroes mutantes, personajes que nacieron con unas capacidades genéticas que les permiten desarrollar ciertos poderes. En este sentido, son distintos a los demás personajes que, usualmente, encontramos en los filmes de superhéroes. Los mutantes tienen un rasgo que los clasifica en un grupo en el cual su identidad está dada por su condición genética singular. Entonces, en el mundo de la ficción no solo son superhéroes, sino que, además, son mutantes.

La segunda característica que permite pensar a los $X$-Men desde la bioética es que, los mutantes hacen parte de poblaciones minoritarias. ${ }^{4}$ Entre las cuales, la más importante es que son de un grupo genético diferente, pero, además, muchos de sus personajes tienen características interraciales, ${ }^{5}$ interespecies (como, por ejemplo, quimeras), ${ }^{6}$ diversidad en las preferencias sexuales, entre otras. Estas características los definen ante sus propios ojos y ante la sociedad como poblaciones que buscan reconocimiento para poder desarrollar sus vidas sin ser perseguidos, atacados o exterminados.

Como grupo minoritario en búsqueda del reconocimiento, $X$-Men se muestra como la historia de la identidad dejando ver tres elementos fundamentales: el primero es la identidad como otredad, el segundo es la diferencia como motor añadido; y el tercero tiene que ver con los códigos de representación del cómic (Velasco, 2015).

Respecto a la identidad como otredad, podemos decir que, para que se dé la identidad es necesaria la diferenciación. En este caso, el mutante posee un gen extra que lo sitúa en un límite marginal, mostrando el miedo a no ser aceptado (por eso, los superhéroes usan máscaras, porque por medio de ellas se esconden). Ese miedo nos lleva al segundo elemento, el motor narrativo del conflicto producido por ser un grupo genético diferente, situándonos en un conflicto social, ya que, como veremos, el mutante tiene miedo de no ser aceptado, a su vez, la sociedad teme al mutante, porque es diferente. El tercer aspecto, la identidad y los códigos de representación del cómic señalan la repetición como elemento determinante, pues lo idéntico repite eso que uno es, de esta forma adquiere lo propio, pues para poder ser reconocido se necesita la continuidad (Velasco, 2015). 
Por esto, en la narrativa de los cómics de superhéroes la repetición entraña historias que, cada vez se mezclan más con lo real para poder seguir teniendo fuerza simbólica ante los espectadores. Particularmente, los $X$-Men muestran relatos de ficción que están mezclados con sucesos históricos como la Guerra Fría, la Guerra de Vietnam, la Segunda Guerra Mundial, la Crisis de los Misiles, entre otros; donde la interacción entre mutantes y humanos cambia el rumbo de esos sucesos. Por ejemplo, Magneto es acusado de matar al Presidente Kennedy o Wolverine combate en las Guerras Mundiales.

Los mutantes tienen poderes y habilidades físicas, químicas, anatómicas, fisiológicas, mentales, intelectuales, psíquicas y fuerza extraordinaria. Algunos pueden controlar elementos como el agua, el aire, el fuego, los metales, el hielo o el clima, usar telepatía y telequinesis. Otros tienen capacidades regenerativas frente a lesiones, inmunidad a enfermedades, longevidad aumentada, y capacidades superiores de adaptación a cualquier entorno (Pedraza, 2017).

Las historias de vida de los mutantes son muy parecidas a las de los humanos, pero se diferencian por la presencia de elementos extraordinarios que, se vuelven notorios a los ojos de los que no son como ellos. Independiente de sus poderes, los mutantes podrían clasificarse en dos grandes grupos: los que visualmente parecen humanos y pasan desapercibidos, y los que su apariencia les impide ocultar que son mutantes. ${ }^{7}$ Esas características ocasionaban que, fuesen vistos por los humanos como seres diferentes, generando hacia ellos rechazo, persecución, incomprensión, maltrato e, incluso, exterminio.

Frente a estas situaciones que dificultaban el desarrollo normal de la vida de los mutantes se abrían dos posibilidades para ellos. La primera, ser educados y protegidos por Xavier, quien velaba por mantener una convivencia pacífica con los humanos, así implicara permanecer en el anonimato y el aislamiento, de modo que sus vidas solo se desenvolverían en la escuela. La segunda, seguir a Magneto, quien pretendía obtener el reconocimiento de los mutantes y reivindicarlos como superiores a los humanos. Magneto es un mutante que había sido maltratado por los humanos, buscaba vengarse de ellos y castigarlos. Además, consideraba que el dominio de la Tierra no debía estar en manos de los humanos, sino de los mutantes que hacen parte de la especie Homo superior, la evolución del Homo sapiens (Malory, 2011).
La idea de los mutantes surge en la década del 60 , época en la que el mundo está dividido en dos bloques: EEUU y la Unión Soviética. Existe una fuerte lucha entre sistemas socio-político-económicos: capitalista y comunista. La sociedad civil empieza a proclamarse alzando su voz, presentando su posición frente (muchos rechazando estos actos) a la intervención del Gobierno de EEUU en un país como Vietnam, el clamor por el reconocimiento y respeto a los derechos civiles de los afroamericanos en EEUU, la protesta por parte de los jóvenes franceses en Mayo del 68, el movimiento Feminista, el movimiento Hippie, las descolonizaciones e independencias en el continente africano.

En esos años y en los posteriores, los fans de los cómics de $X$-Men empiezan a identificar a los mutantes como símbolos de la lucha que un ser diferente lleva para sobrevivir. En los cómics se denuncian problemas como el racismo, la segregación, la homofobia, la xenofobia, donde los gobiernos hacen apuestas políticas de intervención, sin tener en cuenta lo que piensan los ciudadanos. Fue tan fuerte esa identificación que, los mutantes empezaron a asociarse con personajes históricos como Martin Luther King y Malcolm X. Como lo presenta Malory, ven la lucha entre la cooperación no violenta y la confrontación como nada menos que, una alegoría fantástica, al entonces creciente movimiento de los derechos civiles, con el pacífico profesor Xavier representando al reverendo Martin Luther King Jr., ${ }^{8}$ y al justo, pero más militante, Magneto, suplente de Malcolm $\mathrm{X}^{9}$ (2011).

De esta forma, las historias presentadas por Stan Lee en los cómics tendieron a reflejar lo que acontecía culturalmente en su tiempo (Fonseca, 2015). Podemos decir que, de manera anecdótica, en el primer número de $X$-Men, los jóvenes mutantes son recibidos por el gobierno y el público como héroes, con admiración y respeto, como seres que no representaban una amenaza; pero sí resultaban extraños. Esto no será así por mucho tiempo, pues en la edición \# 8 (noviembre de 1964), Hank (Beast) y Bobby (Iceman) logran escapar de una multitud enfurecida que los había atacado y perseguido bajo la idea de que los mutantes eran enemigos (Malory, 2011).

Nuevos personajes e historias van llegando durante décadas a engrosar la producción de cómics de los X-Men hasta el punto en que en 1996 son adaptados para llevarlos a la televisión y en el 2000 se llevan a la pantalla grande. 


\section{Los filmes de X-Men}

Dentro de cada una de las películas, transcurren las historias en determinados tiempos. Aunque, algunas se vinculan con las otras, bien sea por la continuidad temporal entre ellas o por tener como protagonista a uno de los personajes. Por esto, en la figura 1 mostramos cuál es la línea temporal de cada una de las películas. ${ }^{10}$

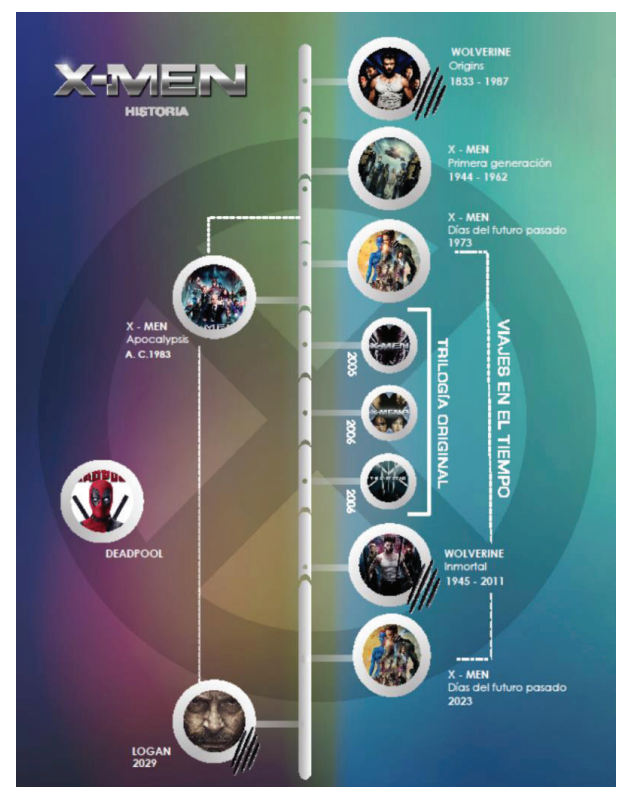

Figura 1. Cronología dentro de los filmes. Fuente: elaboración propia a partir de los datos presentes en las películas.

También debemos tener en cuenta que los cómics de $X$-Men se han adaptado a modo de sagas cinematográficas ${ }^{11}$ en tres grupos (figura 2). El primero está conformado por las tres primeras películas de $X$-Men presentadas al público entre el 2000 y el 2006, donde se puede apreciar una continuidad en los personajes y en las historias. Las siguientes sagas no tienen una continuidad temporal ni de personajes. En ocasiones se muestran personajes con el mismo nombre en películas diferentes, con rasgos distintos, edades que no corresponden a una sola línea temporal ${ }^{12} \mathrm{y}$, por supuesto, esto cambia un poco las historias. Teniendo este referente, la segunda saga tiene como protagonista a Wolverine, quien por la aceptación que parte del público le tiene, probablemente, decidieron darle más fuerza como personaje principal. Esta saga ha sido presentada entre el 2009 y el 2017.

La tercera saga está conformada por tres películas con una línea temporal que se mantiene entre ellas. Los personajes y las historias presentan, a modo de precuela, el origen de los $X$-Men, quienes están bajo la tutoría del
Profesor X, y cómo ocurre el confrontamiento entre humanos y mutantes. En la segunda película, para evitar la puesta en marcha de un programa que busca la destrucción de los mutantes, se realizan viajes en el tiempo. Finalmente, en la tercera película se muestra al primer mutante en la historia y su origen, este mutante busca que la humanidad sea extinguida, acto evitado por la intervención de los X-Men. ${ }^{13}$

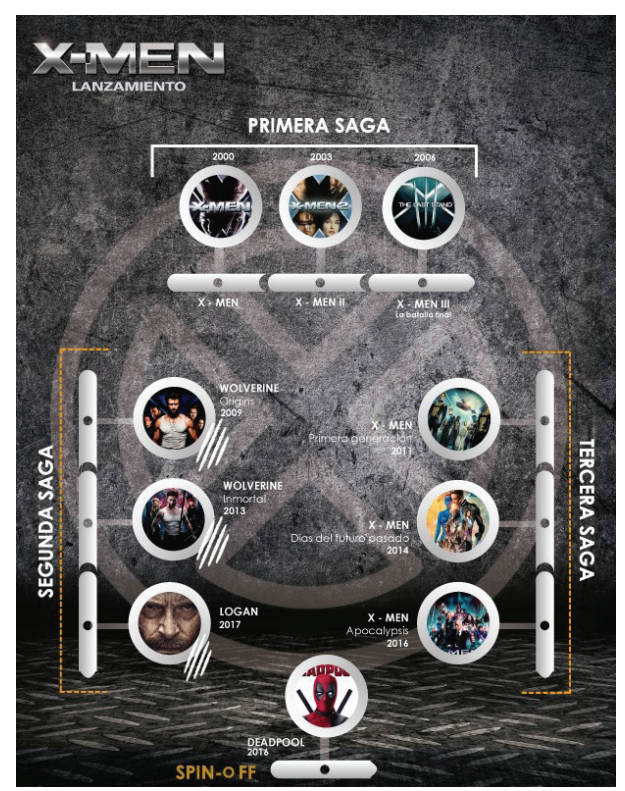

Figura 2. Sagas de X-Men. Se detalla el nombre de cada película, su año de estreno y cuál de las sagas pertenece. Fuente: Elaboración propia con datos de la ficha técnica de cada película.

X-Men: días del futuro pasado, presenta un argumento general que, mantiene las ideas provenientes del cómic nominado de la misma forma. Este apareció entre los meses de enero y febrero de 1981, época en la que los superhéroes tenían rasgos tan humanos que, no parecían personajes de ficción, sino casi de carne y hueso, donde se planteaban dilemas humanos con una profundidad nunca antes vista (Fonseca, 2015). Teniendo en cuenta estos rasgos tan humanos y los dilemas a los que se enfrentan estos superhéroes mutantes, exploremos algunas escenas.

El filme inicia situándonos en diferentes lugares del mundo en el año 2023. Un futuro distópico, lúgubre y hostil, en el que las ciudades han sido destruidas. En medio de la desolación que se percibe, un pequeño grupo de mutantes lucha por sobrevivir. Unos robots llamados Centinelas ${ }^{14}$ los han perseguido para aniquilarlos. En esta lucha no solo han muerto mutantes, también los humanos que los han ayudado. La única forma que encuentran para evitar esta persecución es enviar a Wolverine ${ }^{15}$ al año 1973 para impedir que inicie el Programa 
Centinela. En la figura 3, podemos apreciar a los mutantes que hacen parte del filme.

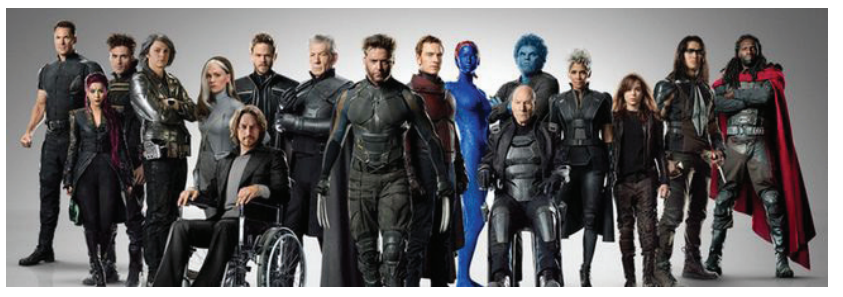

Figura 3. Los mutantes del futuro y del pasado. Mutantes que hacen parte del filme X-Men: días del futuro pasado. Fuente: publicidad de la película.

El título de la película indica que, la historia trascurre entre lo que sucede en el futuro (2023) y el pasado (1973). En su viaje al pasado, Wolverine debe localizar a los mutantes de la época y convencerlos de que lo ayuden a impedir que Mystique ${ }^{16}$ asesine al científico Bolivar Trask ${ }^{17}$ porque al hacerlo, se cancelaría el Programa Centinela. Luego, Wolverine aparece en el futuro, en la Escuela Xavier Para Jóvenes Superdotados, y empieza a ver que todos sus amigos (mutantes) están vivos y que, el pasado cambió, según las noticias que escucha del futuro.

Para poder explorar el filme presentaremos dos grupos de escenas que, consideramos, nos permiten reflexionar bioéticamente sobre las interacciones entre los humanos y los mutantes, y de esta forma, apreciar las relaciones, problemas y demás situaciones que, pueden surgir de esas escenas.

\section{Entre el pasado y el futuro: la distopía de los mutantes}

Las primeras escenas se sitúan en el año 2023. El panorama es oscuro y hostil (figura 4). Se muestran vehículos de carga que van por las calles arrojando cadáveres que parecen ser humanos, se aprecian pilas de ellos por doquier. Un grupo de humanos y mutantes camina custodiado, sugiriendo sometimiento por parte de humanos. Transportadores, los vehículos que movilizan y arrojan centinelas (figura 5), sobrevuelan las ciudades buscando cumplir su función: encontrar mutantes y matarlos. En su mayoría, los mutantes han sido aniquilados. A los sobrevivientes los han marcado con una $M$ al lado derecho del rostro, a la altura de la ceja y el ojo, para ser identificados y señalados como mutantes. Mientras transcurren estas escenas, una voz en off dice:

El futuro, un oscuro y desolado mundo. Un mundo en guerra sufriendo bajas en ambos lados, mutantes y los humanos que se atrevieron a ayudarnos. Enfrentando a un enemigo al que no podemos derrotar. ¿Estamos destinados a recorrer este camino?, ¿destinados a destruirnos como tantas especies antes de la nuestra? o ¿podemos evolucionar justo a tiempo para cambiar... cambiar nuestro destino? ¿Está el futuro marcado? ${ }^{18}$

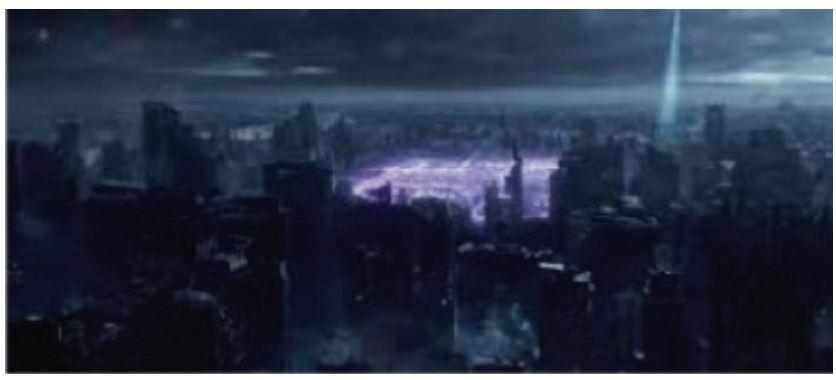

Figura 4. El futuro distópico. Fuente: escena de la película

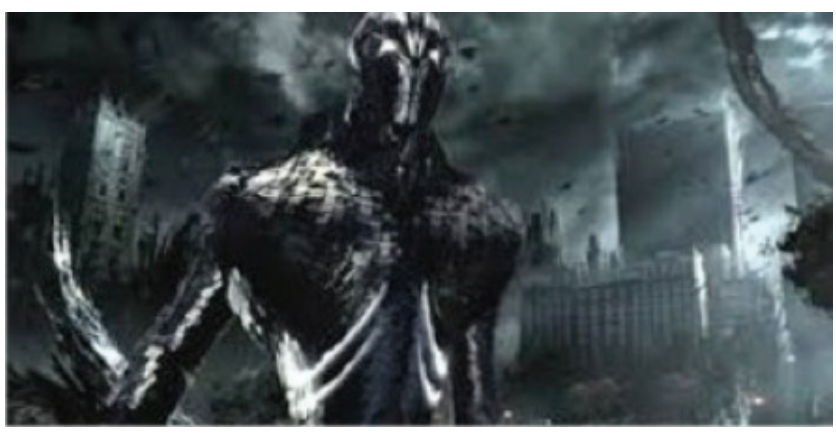

Figura 5. Los centinelas en el futuro. Fuente: escena de la película

Discursos de biopolítica: el Programa Centinela y la protección de la humanidad

El siguiente grupo de escenas ocurre en Washington frente a la Casa Blanca. El presidente estadounidense presenta el Programa Centinela (figura 6), mientras pronuncia el siguiente discurso:

-“Estimados compatriotas: hoy enfrentamos la peor amenaza de nuestra historia: mutantes. Nos hemos preparado para esta amenaza, observen. El mundo jamás volverá a ser el mismo". ${ }^{19}$

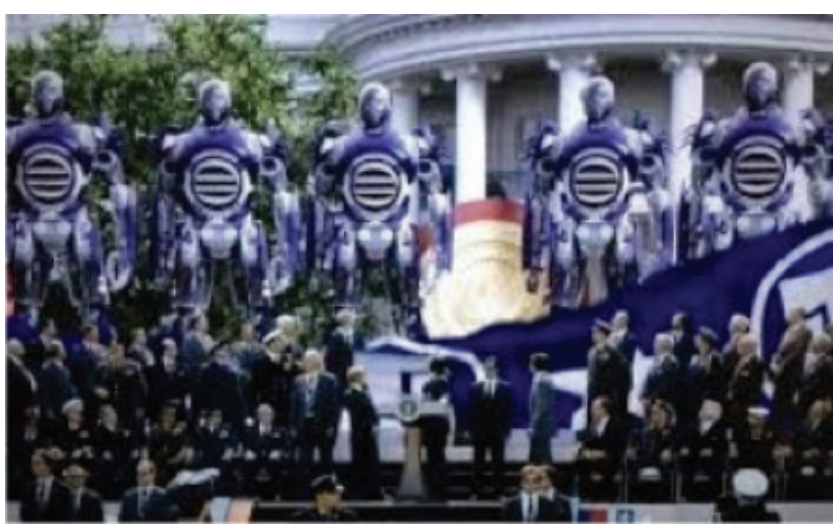

Figura 6. El Presidente de los EEUU presenta a los centinelas. Fuente: escena de la película. 
Durante el discurso del presidente, los centinelas se van mostrando, estos empiezan a activarse por orden de Magneto, quien, sin que nadie se enterase, los había modificado incluyéndoles metal. Los centinelas comienzan a atacar a todos los que estaban presentes en el evento, a humanos y a mutantes por igual. El presidente, su cúpula militar y gubernamental entran a la Casa Blanca dirigiéndose a un búnker. Allí discuten acerca de lo sucedido, de cómo el mundo ahora estaba expuesto a lo que los mutantes quisieran hacer con él, y de cómo el gobierno ya no podía proteger a la especie humana. Esta escena evidencia un pensamiento y actuar biopolíticos que, los podemos entender como la forma de ejercicio del poder político que, tiene por objeto la vida biológica de los hombres (Castro, 2008).

Con su poder de controlar el metal, Magneto atrae el búnker, que está hecho de metal, hacia el exterior de la Casa Blanca. Desprende uno de los lados, dejando al descubierto a quiénes se habían resguardado allí. Manipula las cámaras de video que estaban transmitiendo en vivo el evento, para que lo enfoquen a él, y dice (figura 7):

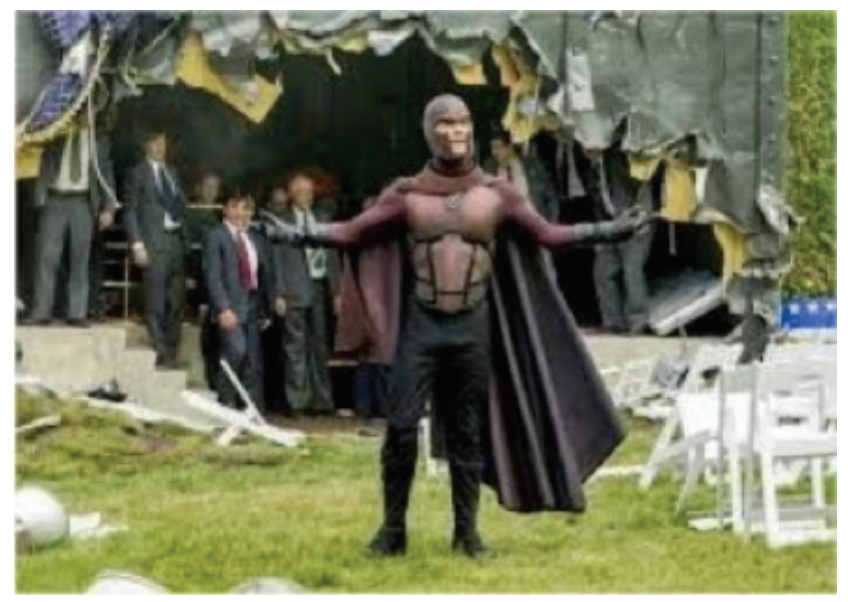

Figura 7. Magneto menciona su discurso ante los ojos del mundo. Fuente: escena de la película.

- "Crearon estas armas para destruirnos. ¿Por qué? Porque les tienen miedo a nuestros dones; porque somos diferentes. La humanidad siempre le ha temido a lo que es diferente, pero vine a decirles, a decirle al mundo: hacen bien en temernos, somos el futuro, nosotros heredaremos esta tierra. Y cualquiera de ustedes que interfiera sufrirá el mismo destino que estos hombres, que ven atrás de mí. Se supone que hoy verían una demostración de su poder; en lugar de eso, les doy una muestra de la devastación que mi raza puede desatar contra la suya. Esta es una advertencia para el mundo. Y a mis hermanos y hermanas mutantes que me oyen les digo esto: basta de ocultarse, no más sufrimiento, han vivido escondiéndose en las sombras y con miedo mucho tiempo. Salgan. Únanse a mí. Luchemos juntos en una fraternidad de nuestra especie, un nuevo mañana da inicio este día”. ${ }^{20}$
Finalmente, Mystique se transforma en el presidente, enfrenta a Magneto y decide no matar a Trask luego de mantener una conversación telepática con Xavier. Mystique deja caer el arma que portaba y se va.

Este escenario fílmico nos ha aportado elementos valiosos como, las percepciones públicas que se pueden tener sobre los seres modificados. Discursos que, fomentan la prohibición, el temor o el apoyo, la necesidad de tener legislaciones y divulgación sobre modificar o no a la especie humana. Surgen de las escenas discusiones, unas explícitas y otras sugerentes, alrededor de preguntas como: ¿debemos permitir la existencia y/o promover la creación de seres humanos modificados ${ }^{21}$ por medio del uso de la biotecnología? ¿La existencia de estos seres pondría en riesgo la vida de los seres humanos? ¿Permitir su existencia implica la extinción de la especie humana? ¿Hasta dónde debería llegar la biotecnología cuando su objetivo de intervención son los humanos? ¿Este tipo de filmes contribuyen a concebir lo bumano de forma distinta? ¿Contribuyen a que cierta postura prevalezca en el espectador?

En el filme logramos apreciar que ${ }^{22}$ se defiende de manera contundente la importancia de salvaguardar $l o$ bumano. Esta idea se hace patente al mostrar en las escenas desoladoras que, aquí denominamos distópicas. Podemos afirmar que, la película evidencia una postura moral explícita que rechaza la idea de pensar lo bumano de forma diferente a la forma en que actualmente lo conocemos como ser natural inmodificable. Que, además, no debe ser intervenido ni trasformado, pues, esto implicaría superar límites que no deben ser superados, porque estaríamos ejerciendo un control absoluto sobre la vida y la supervivencia de la especie.

Ese posible futuro que aguarda a la humanidad como especie si permitimos la existencia de seres modificados, nos sitúa en una discusión biopolítica en la que la vida o la muerte de los modificados está en manos de personajes como Trask (el científico), ${ }^{23}$ el poder militar (Stryker) el poder político (el Presidente de los EEUU) y la difusión de la información (en los medios de comunicación).

Frente a estas preocupaciones, cabe señalar que, si no existe una única forma de entender lo bumano en las producciones cinematográficas o en las discusiones académicas, en las que confluyen diversas posturas filosóficas, sociológicas, antropológicas, biológicas, entre otras, ¿cómo podemos proteger lo bumano si no tenemos una sola forma de concebirlo? ¿Qué deberíamos proteger? Y ¿realmente deberíamos o necesitamos protegerlo?

Además, podemos preguntarnos ¿tenemos derecho a cambiar la naturaleza de los seres humanos? ¿Qué es 
precisamente ser humano? ¿Si cambiásemos, adónde llegaríamos? Si, por ejemplo, tuviésemos que disminuir nuestras capacidades morales para ser más inteligentes, evitar enfermedades o tener una expectativa de vida mayor en mejores condiciones ¿estaríamos dispuestos a pagar el precio? Estamos enfrentando situaciones sin precedentes, lo que nos deja en una posición de incertidumbre frente a lo que nos depara el futuro. Así, siguiendo a Harris (1992):

si dejamos de realizar cambios en los seres humanos, el resultado podría ser simplemente el de garantizar que el futuro sea mucho peor para todo el mundo de lo que tendría que ser. Si hacemos los cambios equivocados podría ocurrir lo mismo. Lo que debemos intentar aprender es a elegir responsablemente, pero no hay ningún sentido en el que no hacer nada necesariamente sea una elección más responsable que hacer algo (p. 23).

Del grupo de escenas que hablan de los viajes del pasado para impedir que Trask ponga en marcha el Programa Centinela, podemos inferir que: a) si permitimos que los mutantes sigan vivos y se reproduzcan, podrían matar a los humanos, y los humanos tal y como los conocemos desaparecerán; b) la especie humana se va a extinguir, porque los mutantes tienen una condición genética mejorada que puede ser la clave para que a no suceda.

La película enfatiza la preocupación por la extinción de la especie humana al señalar la imposibilidad de la coexistencia entre seres modificados y seres no modificados, ya que, esos seres modificados pertenecen a otra especie que, además, goza de un estatus ontológico demasiado cercano al Homo sapiens o incluso superior a él. Según se presenta en el filme, esto conduce al aniquilamiento de los humanos por parte de los mutantes.

Recordemos que, en el filme surgen dos posturas claras personificadas en los líderes mutantes Charles Xavier y Magneto. Xavier buscaba el equilibrio, la supervivencia y la coexistencia pacífica entre mutantes y humanos, Homo superior y el Homo sapiens. Si bien los mutantes reciben una educación enfocada en el manejo y la potencialización de sus capacidades mejoradas, esto no genera que se conciban a sí mismos como mejores o peores que los humanos. Xavier les recuerda que son distintos, lo que no necesariamente implica que se sitúe a unos por debajo de otros.

Magneto busca imponerse ante los humanos (Fonseca, 2015), a quienes rechaza por considerarlos inferiores. Ha sido perseguido y segregado por los humanos, y es un sobreviviente del Holocausto. Sus acciones pretenden reivindicar a los mutantes y ponerlos por encima de los hu- manos, llega así a defender la necesidad de exterminarlos. Los discursos y actos de Magneto hacen que lo veamos como un dictador, pues considera que los mutantes son superiores a los humanos, defiende el tránsito por una fase en la que desaparezcan las desigualdades sociales, permitiendo el establecimiento de un equilibrio que implicaría la pérdida de algunas libertades, así, aunque él se resista a presentarse como un dictador, lo es (Rocha, 2015).

Una idea transversal a toda la película es la contraposición entre riesgos y beneficios a la hora de permitir la modificación de los humanos. Pues señala la problemática de tener seres modificados y seres no modificados y los peligros que entrañan los unos para los otros, por ejemplo, el dominio de unos sobre otros, la persecución, la esclavitud, la segregación y el exterminio. Además, las consecuencias que pueden generarle a una sociedad al permitir que una ideología se vuelva un asunto científico, militar y político. Pues, los mutantes subsistían con los humanos sin problemas, solo cuando Trask los señala como peligrosos y, con su muerte a manos de una mutante, empiezan a ser vistos como seres indeseables que deben exterminarse. Finalmente, los usos de la ciencia y la biotecnología para crear lo que queramos bajo ideologías como las de Trask quien, al señalar/nominar a los mutantes como peligrosos para los otros, a causa de sus características modificadas/mejoradas justifica el que deban ser eliminados.

En los filmes de $X$-Men se hace manifiesta la persecución de cualquiera que tenga una buella genética anormal, especialmente en X-Men dias del futuro pasado, donde se caza a los sospechosos de ser mutantes. Ellos no serían considerados humanos, lo que equivale a decir no protegibles (Rocha, 2015). Esta noción permanece en las películas que hacen referencia a concebir seres distintos a los humanos como hasta hoy los conocemos: la idea de que permitir su existencia genera la destrucción de la humanidad, y la necesidad urgente de anticiparse a esa destrucción mediante la eliminación de los que tienen características modificadas, incluso a los que pueden tener modificaciones en las siguientes generaciones.

Teniendo como referente los grupos de escenas sobre las decisiones que toma el presidente de los Estados Unidos, podemos decir que, las condiciones extremas para llegar a esa toma del poder por parte de unos pocos y de determinar el destino del resto de los existentes se basa en una ideología imperante que se mantiene en las películas de ciencia ficción donde hay una preocupación manifiesta por la necesidad de proteger la naturaleza bumanacontra todas aquellas intervenciones que puedan 
ponerla en riesgo de ser alterada. Y así es como: "el campo de concentración no nace del derecho común, sino del estado de excepción, el mismo que existe en el planeta dominado por los Centinelas, un auténtico "infierno construido por el hombre” (Rocha, 2015, pp. 25-26).

El estado de excepción se establece desde que una ideología imperante se hace la única versión posible. Esta se encarna en los discursos que mantiene Bolivar Trask, al presentar a los mutantes como seres peligrosos que deben ser exterminados, pues al despojarlos de la condición que los hace humanos o cercanos a los humanos, es como se pueden generar decisiones políticas, así,

antes de imponer el estado de excepción, se debe deshumanizaral mutante, aunque sea una contradicción o un imposible y el mutante nunca haya sido considerado como un humano. [...] Esa otra cosa, que sirve para describirlo, es desplazada hacia la inhumanidad, abriéndose así la posibilidad de un exterminio sin consideraciones éticas o morales (Rocha, 2015, pp. 25-26).

Nuestro filme también nos advierte del riesgo al que nos podemos enfrentar al permitir el uso de la biotecnología enfocada en la detección y eliminación de seres (mutantes) modificados genéticamente que, nos impida concebirlos como humanos. Los centinelas identifican/ diferencian a los mutantes mediante la detección del gen $\mathrm{X}$, el gen que hace que sean mutantes -no humanos- clasificándolos como parte de una minoría genética que, además de estar plenamente marcada por medio de la
"M" en la parte superior del párpado, ${ }^{24}$ debe someterse a un grupo de humanos que se ha tomado el poder. Esta toma del poder evoca sucesos históricos en los que el final del camino es el campo de concentración destinado a las minorías, ya sean mutantes o judías, ambas marcadas con el símbolo que las convierte en víctimas (la "M" de Mutantes o la estrella de David judía) (Rocha, 2015).

La referencia a los campos de concentración como destino de las minorías que son perseguidas hasta ser destruidas ha sido estudiada por Hannah Arendt en Proyecto de investigación sobre los campos de concentración, citada por Rocha (2015), donde escribió: "el totalitarismo tiene como objetivo último la dominación total de la experimentación del dominio total, porque, siendo la naturaleza humana lo que es, este objetivo solo puede alcanzarse en las condiciones extremas de un infierno construido por el hombre" (pp. 25-26).

Como menciona Harris, no resulta convincente el hecho de prohibir que se lleven a cabo las intervenciones sobre los humanos. Si, como ya hemos mencionado, estamos en la esfera de la incertidumbre acerca de lo que puede ocurrir, no significa que lleguemos a un punto donde por temor no se haga nada más. Culturalmente, el hombre también ha cambiado y habría que preguntarse si debería servirse de la tecnología para modificar características o capacidades que, antes estaban restringidos, como los que podríamos incluir bajo la noción de lo propiamente bumano.

\section{Referencias}

Biniek, M. y Lynch, J. (2005). Technocomics. En Encyclopedia of science, technology and ethics, pp. 1893-1897. Farmington: Thomson Gale.

Bryce, I., Ziskin, L., (productores) y Raimi, S. (director). (2002). Spider-man[cinta cinematográfica]. Estados Unidos: Marvel Entertainment.

Castro, E. (2008). Biopolítica: de la soberanía al gobierno. Revista latinoamericana de filosofía, 34(2), pp. 187-205. Recuperado de http://www.scielo.org.ar/scielo.php?script=sci_arttext\&pid=S1852-73532008000200001\&lng=es\&tlng=es

Capotorti, F. (1977). Study on the Rights of Persons Belonging to Ethnic, Religious and Linguistic Minorities. Nueva York: United Nations Economic and Social Council, Commission on Human Rights, Sub-commission on Prevention of Discrimination and Protection on Minorities.

Deleuze, G. (2002). Diferencia y repetición. Buenos Aires, Argentina: Amorrortu.

de Miguel Beriain, I. (2011). Quimeras e híbridos: ¿Problema ético o problema para la ética? Dilemata, (6), pp. 101-122. Recuperado de http://dilemata.net/revista/index.php/dilemata/article/view/94/98

Deschênes, J. (1985). Propuesta Relativa a una Definición del Término Minoría. United Nations: Doc. E/CN.4/Sub.2/1985/31.

Eco, U. (1984). Apocalípticos e integrados. España: Editorial Lumen.

Feige, K., Arad, A. (productores) y Favreau, J. (director). (2008). Ironman[cinta cinematográfica]. Estados Unidos: Marvel Estudios.

Fonseca, R. (2015). La patrulla X original. Principio y final. En E. Cucurella y A. Pareja (Ed.), Hijos del átomo. Once visiones sobre la patrulla X, pp. 11-18. Barcelona, España: Alpha Decay. 
Harris, J. (1992) Supermán y la Mujer Maravillosa. Las dimensiones éticas de la biotecnología humana. Madrid: Editorial Tecnos.

Kirby, D. (2008). The Devil in Our DNA: A Brief History of Eugenics in Science Fiction Films. Literature and Medicine 26, no. 1 (Spring 2007), (pp. 83-108). The Johns Hopkins University Press.

Lipovetsky, G., y Serroy, J. (2009). La pantalla global: cultura mediática y cine en la era hipermoderna. Barcelona: Anagrama.

Malory, M. (2011). The Characters and their universe. Nueva York: Marvel Characters, Inc Barnes \& Noble, Inc.

Morris, T. y Morris, M. (2010) Los superbéroes y la filosofía. Barcelona, España: Blackie Books.

Pedraza, N. (2017). X-Men y la experimentación científica. VI Congreso online de Ética y Cine, Agosto-Octubre 2017. Recuperado de: http://www.eticaycine.org/X-Men

Rocha, S. (2015). El futuro: un mundo oscuro y desolador. En E. Cucurella y A. Pareja (Ed.), Hijos del átomo. Once visiones sobre la patrulla X, pp. 19-33. Barcelona, España: Alpha Decay.

Singer, B., Kinberg, S., Donner, L., Parker, H. (productores) y Singer, B. (Director). (2014). X-Men: días del futuro pasado [cinta cinematográfica]. Estados Unidos y Reino Unido: Twenty Century Fox Home Entertainment.

Shuler Donner, L., Kinberg, S., Reynolds, R. (2018). Deadpool 2 [cinta cinematográfica]. Estados Unidos: Kinberg Genre, Maximum Effort, The Donners' Company, TSG Entertainment, Marvel Entertainment.

Shuler Donner, L.,Kinberg, S., Singer, B. (productores) y Kinberg, S. (director). (2019). Dark Phoenix [cinta cinematográfica]. Estados Unidos: Marvel Entartainment, 20th Century Fox, Walt Disney.

Velasco, U. (2015). Hombres en la encrucijada. En E. Cucurella y A. Pareja (Ed.), Hijos del átomo. Once visiones sobre la patrulla $X$, pp. 55-64. Barcelona, España: Alpha Decay.

Winter, R., Jackman, H., Shuler Donner, L., Palermo, J., Donner, R. (productores) y Hood, G. (director). (2009). X-Men Origins: Wolverine [cinta cinematográfica]. Estados Unidos: Twenty Century Fox, The Donners' Company, Seed Productions.

Sobre las características de los X-Men. http://marvel.com/characters

\footnotetext{
1 https://www.imdb.com/search/title?title_type=feature\&keywords=superhero\&sort=your_rating_date,asc\&start=201\&explore=genres\&ref_=adv_nxt

2 https://www.boxofficemojo.com/genres/chart/?view=main\&sort=gross\&order=DESC\&pagenum=1\&id=superhero.htm

3 Distopía se entiende como una sociedad ficticia indeseable en sí misma.

4 Podría definirse como un grupo de personas que difieren de la mayoría porque cuentan con características diferentes como la raza, la etnia, la religión, la condición sexual o incluso el idioma que tienen. Así, tenemos minorías étnicas, culturales, religiosas. Las minorías incluyen a los grupos que son menos numerosos que el resto de la población de un estado; no están en una posición dominante, residen en el Estado, siendo ya sea ciudadanos o un grupo con vínculos estrechos y de larga data con el Estado, poseen características étnicas, religiosas o lingüísticas que difieren de aquellas del resto de la población. Y muestran un sentido de solidaridad, aunque solo sea implícito, dirigido hacia la conservación de su identidad colectiva distintiva (Capotorti, 1977; Deschênes, 1985). Por lo general se reconoce que los grupos minoritarios incluyen minorías nacionales, étnicas, culturales, lingüísticas y religiosas, así como algunos inmigrantes, refugiados, pueblos indígenas y tribus. También es importante tener en cuenta que es más probable que las minorías sean discriminadas o marginalizadas y pueden desarrollar un aumento de lealtad hacia el grupo como resultado de las relaciones discriminatorias y marginalizadas dentro del estado.
} algunos.

Cuenta con protagonistas latinos: Sunspot, afrodescendientes: Bishop, Storm, Spyke, asiáticos: Blink, Warpath, por mencionar

6 Hay organismos que provienen del cruce de animales de diferentes especies, como es el caso de perros con lobos, o caballos con burros. También, podemos encontrar quimeras artificiales, creadas a partir, por ejemplo, de la transferencia de células cerebrales de fetos de codorniz al cerebro de fetos de pollo. Es más, algunos científicos han transferido células madre embrionarias humanas a blastocitos de ratón (de Miguel Beriain, 2011). En la mitología también encontramos seres formados por diferentes animales con cabeza de león, cuerpo de cabra y cola de serpiente, o seres con varias cabezas de diferentes especies. Para el caso de los X-Men, tenemos personajes como Beast: hibrído entre simio y humano, Toad: híbrido entre humano y sapo. Por mencionar algunos.

\section{Como Mystique y Nightcrowler.}

8 Pastor estadounidense que luchó por el reconocimiento de los derechos civiles de los afroamericanos, rechazó la Guerra de Vietnam, la segregación, la pobreza, las malas condiciones laborales de los empleados, todo esto por medios no violentos, lo que hizo que le otorgaran el Premio Nobel de Paz en 1964, fue asesinado en 1968.

$9 \quad$ Orador y ministro religioso estadounidense que defiende los derechos de los afroamericanos, aunque algunos consideran que se fue al extremo de declarar, que la vía no violenta, no era la solución y que era necesaria una emancipación de los afrodescendientes tomando el control del gobierno y las comunidades. 
Cabe mencionar que nuevas películas se han ido generando como Deadpool 2 (Leitch, 2018), Dark Phoenix (Kinberg, 2019)

11 Saga: conjunto de filmes que comparten personajes o el argumento principal. Estas obras, que aparecen a lo largo de los años, conforman un universo de ficción, donde hechos contados en una obra pueden remitir a otros narrados en libros o películas precedentes.

12 Por mencionar un ejemplo, podemos ver las diferencias entre el William Stryker de X-Men: Orígenes Wolverine (Hood, 2009) y el de X-Men: días del futuro pasado. Representado por actores diferentes y con rasgos que evidencian la discontinuidad entre las sagas.

13 Cabe señalar que, posteriormente, se han lanzado más películas abriendo nuevas líneas temporales como lo son: Deadpool 2 y DarkPhoenix que hace parte de la tercera saga.

14 Centinelas: Son robots/armas que pueden copiar las características de los mutantes y se enfrentan con ellos hasta matarlos. Fueron creados por Bolivar Trask para cazar mutantes y eliminarlos. Hacen parte del Programa Centinela que busca identificar el gen $\mathrm{x}$ y destruir a todo el que lo posea o pueda desarrollarlo. http://marvel.com/characters/2045/sentinel

15 Logan/Wolverine: Mutante que posee la capacidad de regenerar áreas dañadas o destruidas de su estructura celular a un ritmo mucho mayor que el de un humano ordinario. Tiene inmunidad a venenos, muchas medicinas y enfermedades. No envejece al ritmo normal de otros seres vivos, él lo hace más lento. Tiene garras de metal que puede desplegar de sus manos. Fue sometido por Stryker a un experimento para Crear el Arma X, donde le cambiaron su aparato óseo por uno de adamantium, un metal indestructible". http://marvel.com/characters/66/wolverine

16 "Raven/Mystique: Mutante que puede cambiar los átomos de su cuerpo para duplicar a cualquier humanoide de cualquier sexo, llevando cualquier tipo de ropa. Precisamente ella puede duplicar otra persona patrón de retina, dedos, palma, patrones de poros de la piel y las cuerdas vocales. Tiene retraso de la edad, mayor curación e inmunidad a los medicamentos y venenos. En los filmes, aparte de adoptar la apariencia física de quien imita, para el caso de los mutantes, logra adoptar sus poderes también”. http://marvel. com/characters/1552/mystique

17 "Bolivar Trask: Humano, antropólogo y científico que crea el Programa Centinela y experimenta con mutantes".

18 Singer, B., Kinberg, S., Donner, L., Parker, H. (productores) y Singer, B. (Director). (2014). X-men: días del futuro pasado [cinta cinematográfica]. EEUU y Reino Unido: Twenty Century Fox Home Entertainment.

19 Singer, B., Kinberg, S., Donner, L., Parker, H. (productores) y Singer, B. (Director). (2014). X-men: días del futuro pasad [cinta cinematográfica]. EEUU y Reino Unido: Twenty Century Fox Home Entertainment.

20 Discurso de Magneto. Singer, B., Kinberg, S., Donner, L., Parker, H. (productores) y Singer, B. (Director). (2014). X-men: días del futuro pasado [cinta cinematográfica]. EEUU y Reino Unido: Twenty Century Fox Home Entertainment.

21 De acuerdo al contexto que hemos venido presentando, los humanos modificados o mejorados están personificados por los mutantes.

22 Y nos atrevemos a afirmar que en todos los filmes de superhéroes y en los que muestran la intervención de la biotecnología sobre la vida humana.

$23 \mathrm{Al}$ mostrar a los mutantes como seres peligrosos, sencillamente, por tener unas características diferentes, $\mathrm{y}$, al defender la idea de que, permitir su existencia implicaba la desaparición de la especie humana.

24 En el cómic los mutantes se marcaban con una $\mathrm{M}$, los humanos con una $\mathrm{H}$ y los que podrían tener descendientes mutantes con una $\mathrm{A}$, incluso en generaciones muy posteriores. Esto permite plantearnos el interrogante ¿estaríamos dispuestos a permitir marcas identificadoras a aquellos seres que fueran modificados genéticamente? 